\title{
EDUCOMUNICAÇÃO COMO RECURSO DE MIDIARTIVISMO
}

\author{
Ricardo Oliveira de Freitas
}

\section{RESUMO}

Analiso iniciativas de midiartivismo como práticas educomunicativas, a fim de compreender a importância da interseção entre arte e mídia para a elaboração de projetos pedagógicos e, mesmo, políticos. Para tanto, apresento resultados de análises elaboradas acerca de artistas e coletivos de arte compromissados com ações que promovem discussões sobre temas como gênero, sexualidades, raça, etnia e localismos, com 0 intuito de contribuir para o fortalecimento da democracia, a conquista da cidadania, o desenvolvimento humano e a equidade de direitos. Ao incentivar o uso artístico das tecnologias como instrumento político, afirmo que esse tipo de ativismo promove uma militância que é sempre formativa e pedagógica.

Palavras-chave: Midiartivismo. Educação popular. Educomunicação.

\section{EDUCOMMUNICATION AS A RESOURCE OF MEDIARTIVISM}

\begin{abstract}
I analyze mediartivism initiatives as educommunication practices in order to understand the importance of the intersection between art and the media for the elaboration of pedagogical and even political projects. I present results of elaborated analyzes of artists and art and culture collectives committed to actions that promote discussions on themes such as gender, sexuality, race, ethnicity and localism aiming at contributing to the strengthening of democracy, human development and fairness of rights. By encouraging the artistic use of technologies as a political instrument, I affirm that this type of activism promotes a kind of militancy that is always formative and pedagogical.
\end{abstract}

Keywords: Mediartivism. Popular education. Educommunicaçtion.

\section{EDUCOMUNICACIÓN COMO RECURSO DE MEDIOARTIVISMO}

\section{RESUMEN}

Analizo iniciativas de medioartivismocomo prácticas educomunicativas, a fin de comprender la importancia de la intersección entre arte y medios para la

1 Doutor em Comunicação e Cultura - Universidade Federal do Rio de Janeiro, ECO/UFRJ. Professor Titular - Universidade do Estado da Bahia, Programa de Pós-Graduação em Estudo de Linguagens - PPGEL/UNEB (Salvador, BA, Brasil). ORCID: https://orcid.org/0000-0002-75284488. E-mail: ricofrei@gmail.com 
elaboración de proyectos pedagógicos e políticos. Para ello, presento resultados de análisis elaborados acerca de artistas y colectivos de arte comprometidos con acciones que promueven discusiones sobre temas como género, sexualidades, raza, etnia y localismos, con el propósito de contribuir al fortalecimiento de la democracia, la conquista de la ciudadanía, el desarrollo humano y la equidad de los derechos. Al incentivar el uso artístico de las tecnologías como instrumento político, afirmo que ese tipo de activismo promueve una militancia que es siempre formativa y pedagógica.

Palabras clave: Mediosartivismo. Educación popular. Educomunicación.

\section{INTRODUÇÃO}

Os debates sobre educomunicação têm sido sustentados, comumente, em torno de dois eixos fundamentais. O primeiro, diz respeito ao (bom) uso das mídias, isto é, à educação que se preocupa com o uso da mídia pelo espectador, aos ensinamentos sobre como utilizar a mídia e fazer leituras críticas do que ela produz e veicula.

A importância desse debate reside, sobretudo, no fato de que, no Brasil, a mídia é o principal instrumento de formação da opinião pública. Aqui, as muitas teorias da comunicação que veem o espectador como mero sujeito passivo frente aos meios de comunicação dominantes, encontram solo fértil para pensar as questões relacionadas à persuasão, à manipulação, à dominação e, por extensão, às formas de resistência e combate à onipotência das grandes empresas de comunicação, a grande mídia. Nesse sentido, esse enfoque acredita numa pedagogia que contribui para combater a onipotência das fontes de informação e sistemas de representação não democráticos. Ainda dentro desse enfoque, considera-se o fato dessa ser uma nação que abriga a segunda maior emissora de televisão do mundo, que transmite sinal para e é assistida pela quase totalidade da população brasileira, por quase todo território nacional - além de ser transmitida no exterior. Desse modo, considerando a expressividade de abrangência dessa emissora, o planejamento de modos de produção que se distanciem de um modelo de televisão geralista, com conteúdos unívocos em prol de uma produção plural, diversa, que valoriza as múltiplas 
realidades regionais é tarefa de um bom planejamento em educomunicação.

O segundo eixo diz respeito ao uso da mídia na educação, isto é, do uso dos instrumentos e tecnologias de informação e comunicação como recursos para promover modos e formas de aprendizagem. Aqui, se inclui a produção de materiais de ensino, ou seja, a geração de conteúdos educativos, que, nos últimos anos, tem apresentado para o mundo produtos cada vez mais e mais criativos e instigantes.

Os dois casos levam à preocupação com o debate sobre a gestão da mídia e a democratização da comunicação, já que ressignificam o lugar do espectador, do público, da audiência, do ouvinte, do leitor, do povo frente à mídia e às grandes empresas de comunicação e de produção de conteúdos. Por isso, pensar a educomunicação é pensar sobre modos de comunicação autóctone, inclusiva, democrática, comunitária e popular.

Outro enfoque diz respeito às ações de midiartivismo, que reúnem numa só iniciativa recursos de mídia, expressões em arte e formas de ativismo, resistência e luta, simbolizadas pela equação mídia + arte + ativismo. Essas ações têm obtido o caráter de educar, de propiciar aprendizagem sobre novos modos de ser, contribuindo para um novo olhar sobre realidades políticas, culturais e econômicas pouco visibilizadas, acerca da vida social dos menos favorecidos, das populações desprestigiadas, desprivilegiadas, dos grupos e comunidades subalternizadas. Por isso, defendo a ideia de que práticas e iniciativas de midiartivismo são ações educativas, já que promovem procedimentos didáticos e de aprendizagem, mesmo que sejam procedimentos distintos dos utilizado pelo ensino formal e convencional, historicamente hegemônico.

Ao tornar públicas suas causas, seus problemas e suas prioridades e divulgar suas expectativas e demandas, grupos e comunidades que fazem uso de práticas midiartivista contribuem para um tipo de pedagogia aos moldes do que foi defendido pelos muitos conceitos, correntes, escolas e teorias pedagógicas e comunicacionais, que refletiram sobre práticas de ensino e aprendizagem contra-hegemônicos, como a pedagogia do 
oprimido, a pedagogia crítica, a educação popular, a comunicação comunitária feita por grupos subalternizados, marcados por recortes de minoridade tais como raça, sexualidade e classe e que reinscrevem práticas pedagógicas e comunicacionais e metodologias baseadas na dialogicidade como essência da prática libertadora, como proposta por Paulo Freire (1983).

Esse é o caso dos artistas e dos grupos de artistas e coletivos midiartivistas que atuam pelo Brasil afora. Ao exporem suas causas, artistas e coletivos promovem um tipo de prática pedagógica que se propõe a provocar uma intervenção nos modos com que a sociedade se vê e vê seus diversos grupos e comunidades.

Como a educomunicação é um tipo de prática metodológica, os coletivos também transmitem conhecimento sobre o uso de tecnologias, num tipo de educação não formal, horizontal, multimídia, interdisciplinar, inclusiva e colaborativa, a fim de contribuir para o protagonismo de indivíduos integrantes de grupos subalternizados.

Nesse texto, apresento minhas considerações acerca do tema, utilizando, como campo empírico não somente as iniciativas de coletivos midiartivistas, mas, também, práticas artísticas de artistas e performers brasileiros, que, aqui, considerarei como práticas midiartivistas e, por isso, educativas.

\section{É SOM DE PREto, De faVelado, MAS, QUANDO TOCA, NINGUÉM FICA}

\section{PARADO}

Chamo midiartivismo as ações criadas por artistas e grupos de artistas, chamados coletivos, que se organizam usando a mídia digital e se fazem presentes em plataformas de redes sociais a fim de ocupar espaços públicos. De modo geral, são ações criadas por artistas ou coletivo de artistas, educadores e militantes, que fazem uso de recursos de mídia e de expressões artísticas para promover o ativismo e para incrementar ações políticas, num tipo de pedagogia feita por integrantes de grupos e comunidades subalternizadas, acerca de realidades marcadas pelos 
clássicos recortes de minoridade. Por isso, pode-se afirmar que o midiartivismo é um tipo de educomunicação que exalta a pedagogia do oprimido, a pedagogia popular e a comunicação comunitária, a fim de tornar públicos seus produtores e idealizadores, ao falar para o mundo: quem sou eu, o que eu quero e como você deve se relacionar comigo, com base no princípio da igualdade de direitos e de respeito e tolerância à diversidade.

O que se vê é um tipo de metodologia, que utiliza recursos de comunicação e expressões em arte para promover a criação de ações políticas que contribuem para a luta contra a discriminação racial, de classe, sexual, de gênero e religiosa. É música, é arte, a favor do ensino progressista, de uma pedagogia da autonomia que, como propõe o mesmo Freire (2010), deve priorizar o dialogismo e processos de aprendizagem que se baseiem na experiência adquirida na sociedade, na vivência junto à coletividade, no aprimoramento de elaboração da criticidade e na criação de oportunidades para a construção de saberes.

Muitas têm sido as contribuições que o debate em torno das práticas e iniciativas de educomunicação tem suscitado para a organização e fortalecimento de grupos populares, dos movimentos sociais e para a redução da desigualdade social e econômica. Aspectos relacionados às ações colaborativas, compartilhadas e coletivas têm sido corriqueiramente associados à dimensão inclusiva de tal tipo de educação e comunicação, que, não por acaso, reelabora uma contrainformação sobre grupos e comunidades histórica e, negativamente representados pela mídia hegemônica. Ações midiartivistas também contribuem para a emergência da representatividade de grupos excluídos de projetos de visibilidade e representatividade. Para esses grupos, as ações midiartivistas auxiliam na obtenção de reconhecimento junto à esfera pública política, auxiliando, por extensão, na aquisição da cidadania, na melhoria da qualidade de vida e no desenvolvimento humano. Nesse sentido, é como projeto impulsionador de políticas de representação positivas que, tanto a educomunicação como o midiartivismo, têm se estruturado como potência inclusiva. 
Projetos educomunicativos e midiartivistas, no que são produzidos pelos próprios sujeitos preteridos dos processos de produção de representações que positivam e dignificam determinados grupos, comunidades e segmentos populacionais (e ignorados pelos projetos de construção de representações positivas construídas pela grande mídia), transformam-se em projetos contra-hegemônicos, radicais e alternativos, voltados para a organização dos grupos em coletivos e para o fortalecimento das estratégias de promoção de práticas inclusivas. No caso dos artistas e coletivos analisados, as representações negativas recaem sobre as suas condições de raça e etnia, gênero e sexualidade, classe, localismos, assim como, pertença religiosa.

O texto extraído do site da artista Linn da Quebrada sobre projeto intitulado "Bixaria Bocket Show" é esclarecedor nesse aspecto.

\begin{abstract}
Uma performance cênica musical pautada num repertório autoral atravessado pelas questões relativas ao corpo preto, periférico, bixa e transviadx da artista. Nasce como grito, até então entalado na garganta. Nasce da necessidade de ter voz, de ser ouvida. Seu objetivo primeiro é empoderar corpos, é produzir encontros - seja nas ruas, festas, fervo - que modifiquem nossas relações ou o olhar que temos sobre elas e nós mesmas. É resistência! ${ }^{2}$
\end{abstract}

Como o texto diz, o objetivo do projeto é empoderar, produzir encontros e contribuir para a transformação de corpos dissidentes e para a tolerância e respeito à diversidade de modos de vida e visões de mundo. Esses objetivos muito se aproximam dos aspectos que caracterizam a educação popular, que tem como projeto essencial a valorização dos saberes do povo para a construção de novos saberes.

"Bixa Preta", música composta e interpretada pela artista paulista Linn da Quebrada, é uma "aula" sobre ser bixa, preta e favelada. Num determinado trecho da música, Linn pede que seu ouvinte sente e ouça o que ela tem a dizer, num tipo de metodologia corriqueiramente aplicada pelas escolas formais, de caráter autoritário. Mas, aqui, Linn, contrariamente,

\footnotetext{
2 Disponível em: <https://www.linndaquebrada.com/projetos>. Acesso em: 14 fev. 2019.
} 
apresenta conteúdo absolutamente inovador. Esse conteúdo é a arma que destruirá o macho, ao que parece, homofóbico, misógino e racista.

\author{
Bixistranha, loka preta da favela; \\ Quando ela tá passando todos riem da cara dela; \\ Mas, se liga macho, presta muita atenção; \\ Senta e observa a sua destruição ${ }^{3}$.
}

\title{
A EDUCAÇÃO QUE TRANSFORMA
}

A educação popular é sempre um projeto colaborativo no sentido de que incentiva e valoriza o diálogo e a participação popular e comunitária nos processos de construção do conhecimento e de aprendizagem, num tipo de projeto que nos apresenta "a noção de aprender a partir do conhecimento do sujeito, a noção de ensinar a partir de palavras e temas geradores, a educação como ato de conhecimento e de transformação social e a politicidade da educação" como atributos da educação popular para a pedagogia crítica universal. (GADOTTI, 2000, p. 6).

Fora isso, a educação é um lugar importante para apresentar o novo, o estranho, o diferente e enquadrá-lo na ordem da normalidade, do cotidiano ordinário.

Reconhecendo que o tema das minorias e dissidências sexuais tem tomado a cena e assumido ares ordinários, num debate bem mais visível junto à esfera pública do que há algumas décadas, além de entender que os binarismos que norteavam as posições de gênero e sexuais "fugiram das raias" da dualidade e se esvaíram a partir de expressiva diversidade de identidades sexuais e de gênero, a teórica Guacira Louro questiona:

Como um movimento que se remete ao estranho e ao excêntrico pode se articular com a Educação, tradicionalmente o espaço da normalização e do ajustamento? Como uma teoria não-propositiva pode 'falar' a um campo que vive de projetos e de programas, de intenções, objetivos e planos de ação? Qual o espaço, nesse campo usualmente voltado ao disciplinamento e à regra, para a transgressão e para a contestação? Como romper com binarismos e pensar a sexualidade, os gêneros e os corpos de uma forma plural, múltipla e cambiante? Como traduzir a teoria queer para a prática pedagógica? (2013).

\footnotetext{
${ }^{3}$ Bixa Preta. Música, letra e interpretação de Linn da Quebrada. Gravadora Showlivre. 2017.
} 
Para Louro, a teoria queer é importante política para a educação, já que nos permite refletir sobre "a ambiguidade, a multiplicidade e a fluidez das identidades sexuais e de gênero", assim como "sugere novas formas de pensar a cultura, o conhecimento, o poder e a educação" (LOURO, 2001).

O educador Tomaz Tadeu da Silva define a teoria queer como sendo a promotora de "uma verdadeira reviravolta epistemológica".

\begin{abstract}
A teoria queer quer nos fazer pensar queer (homossexual, mas também "diferente") e não straight (heterossexual, mas também "quadrado"): ela nos obriga a considerar o impensável, o que é proibido pensar, em vez de simplesmente considerar o pensável, o que é permitido pensar. (...) O queer se torna, assim, uma atitude epistemológica que não se restringe à identidade e ao conhecimento sexuais, mas que se estende para o conhecimento e a identidade de modo geral. Pensar queer significa questionar, problematizar, contestar, todas as formas bem-comportadas de conhecimento e de identidade. A epistemologia queer é, neste sentido, perversa, subversiva, impertinente, irreverente, profana, desrespeitosa (SILVA, 2007).
\end{abstract}

Entender o modo como esse tipo de projeto pedagógico (re) organiza o espaço público e contribui para a construção de movimentos associativos de pertença identitária, contribui, sobremaneira, para o reconhecimento do importante papel das artes, da comunicação e dos seus meios para a concretização de um modelo justo de sociedade que contemple a inserção de grupos e comunidades (até então) invisibilizadas junto à esfera pública política e à esfera de visibilidade pública, por conta de uma eficaz política de exclusão e de representações pejorativas e desqualificadoras.

Por isso, pensar a educomunicação nos termos de uma teoria queer apresentada pelas inciativas midiartivistas é pensar sobre formas de fortalecimento da democracia. Também por isso, entende-se que a ideia da educomunicação está estritamente relacionada à projeção e ao reconhecimento na esfera de visibilidade midiática, que, nesse sentido, chega mesmo a traduzir a ideia de esfera pública política constituída.

Se antes, o que se via era a expressividade de redes de solidariedade organizadas entre grupos e comunidades juridicamente vulneráveis, sociedade civil, terceiro setor e Estado, agora, num tipo de redução à condição mínima, o que se vê são coletivos, pequenos grupos de artistas ou 
artistas solo fazendo emergir, através do midiartivismo, vozes subalternizadas e invisibilizadas, excluídas dos projetos de cidadanização e do processo civilizatório brasileiro.

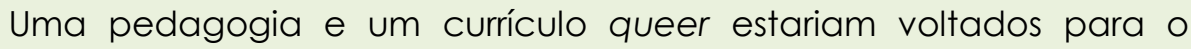
processo de produção das diferenças e trabalhariam, centralmente, com a instabilidade e a precariedade de todas as identidades. Ao colocar em discussão as formas como o 'outro' é constituído, levariam a questionar as estreitas relações do eu com o outro. A diferença deixaria de estar lá fora, do outro lado, alheia ao sujeito, e seria compreendida como indispensável para a existência do próprio sujeito: ela estaria dentro, integrando e constituindo o eu. A diferença deixaria de estar ausente para estar presente: fazendo sentido, assombrando e desestabilizando o sujeito. Ao se dirigir para os processos que produzem as diferenças, o currículo passaria a exigir que se prestasse atenção ao jogo político aí implicado: em vez de meramente contemplar uma sociedade plural, seria imprescindível dar-se conta das disputas, dos conflitos e das negociações constitutivos das posições que os sujeitos ocupam (LOURO, 2001).
\end{abstract}

\title{
ALÉM DOS MUROS DA ESCOLA
}

Martin-Barbero (2004) chama a atenção para o fato de que as alternativas de comunicação popular (aonde eu incluo a educação popular, ou melhor, a educomunicação) não devem, necessariamente, ser marginais às grandes mídias; ou, para o caso da educação, aos modelos canônicos de metodologias e currículos. Podem mesmo apoderar-se de traços de cultura massiva (que não é problema). Entretanto, devem atentar para o fato de que as culturas populares não são homogêneas, tal qual o discurso construído pela grande mídia e pelo cânone. O problema reside no fato de que no que é produzida para massificação e controle das massas, a cultura massiva tende a negar as diferenças, fazendo com que desapareçam por assimilação e pela homogeneização.

Considerando que mesmo o gosto popular está moldado pela cultura de massa, reconhecemos que a comunicação e a educação serão alternativas ao assumirem a complexidade dos processos de massificação da cultura (e formação da comunicação massiva) que são estruturados na quase negação do popular. Digo, quase; já que entendo que numa análise aguçada dos complexos processos de formação da cultura massiva, 
podemos perceber traços de popularidade, "de códigos e dispositivos em que se imbricam a memória popular e o imaginário das massas" (MartinBarbero, 2004, p. 7). De onde advém a necessidade de se tecer uma análise aprofundada sobre a totalidade das estruturas de produção da informação e do conhecimento.

Por isso, afirmo que o midiartivismo como projeto educador é importante lugar para dar visibilidade a causas as mais diversas, plurais, variadas, fugindo dos modelos de projetos de ensino enquadrados em currículos fechados e distanciados de realidades não-hegemônicas.

Por sua vez, a arte, no que adquire, além das suas dimensões estéticas, uma dimensão política, vai contribuir para a criação de processos de visibilidade e inserção social, através da criação de expressões inventivas e representações positivas e dignificantes, distanciadas dos clássicos modelos de representação que normalmente são produzidos acerca dos grupos minoritários através dos recorrentes discursos pejorativos e desqualificadores.

A arte ativista, isto é, a arte como ativismo, funciona como importante ferramenta de difusão cultural, contribuindo, sobremaneira, para a inclusão de grupos subalternizados e para a normalização ou, como prefiro, a rotinização de modos de vida alijados da esfera pública política e da esfera de visibilidade midiática. Nesse sentido, pode-se mesmo afirmar que a arte midiativa, não somente insere no mainstream culturas colocadas às margens, mas, sobretudo, cria uma nova esfera pública, política e midiática, que desloca as margens ou ainda, que faz das margens centro.

Ao afirmar que a arte inclui (através da rotinização de modos de vida alheios), chamo a atenção para o caráter pedagógico da arte, já que além do seu papel criativo e dos seus atributos estéticos, a arte serve como importante ferramenta para construir identidades, demarcar diferenças e estabelecer fronteiras literais e simbólicas.

Como ilustração, apresento o caso de três artistas com posturas midiartivistas que, não por acaso, são educadores e têm assumido o compromisso de fazer das suas artes expressões estéticas que não somente 
denunciam desigualdades, mas, sobretudo, que combatem essas mesmas desigualdades através de processos educativos e formativos.

Inicio com o artista multimídia Tiago Santana. Negro, homossexual, nascido no seio de uma família pobre do interior da Bahia, Tiago, mais conhecido pelas suas performances, chama a atenção em suas obras para a condição de ser negro no Brasil contemporâneo. Para tanto, o artista dialoga com o passado brasileiro, através da história da escravidão, que permite ao fruidor da sua obra refletir sobre os resquícios de colonialidade presentes na realidade brasileira ainda hoje, e no lugar reservado a descendentes de africanos na racista e desigual sociedade brasileira. Parte da obra do artista diz respeito aos tipos de trabalho submetidos aos escravizados ou à economia açucareira e seu importante papel para subjugar africanos e seus descendentes.

Na obra intitulada Refino \#4, o artista cobre com açúcar imagens criadas pelo pintor Jean-Baptiste Debret, uma das maiores referências em termos de iconografia produzida sobre o Brasil colonial e seu sistema escravocrata. Tiago não se atém somente à história do Brasil colonial. O Brasil contemporâneo também é tema do seu trabalho, mesmo que ecos do Brasil escravocrata, do passado, continuem, ainda aqui, presentes 4 .

A performance intitulada Apagamento \# 1 é exemplo. Faz referência à Chacina do Cabula, ocorrida no bairro de mesmo nome, situado na periferia de Salvador, quando doze jovens negros foram barbaramente assassinados pela polícia do estado.

A obra de Tiago é boa ilustração das iniciativas que utilizam expressões em arte a favor da causa inclusiva, democrática e antirracista.

\footnotetext{
4 Todas as imagens de obras aqui apresentadas foram extraídas de páginas dos artistas ou de galerias disponíveis na Internet.
} 


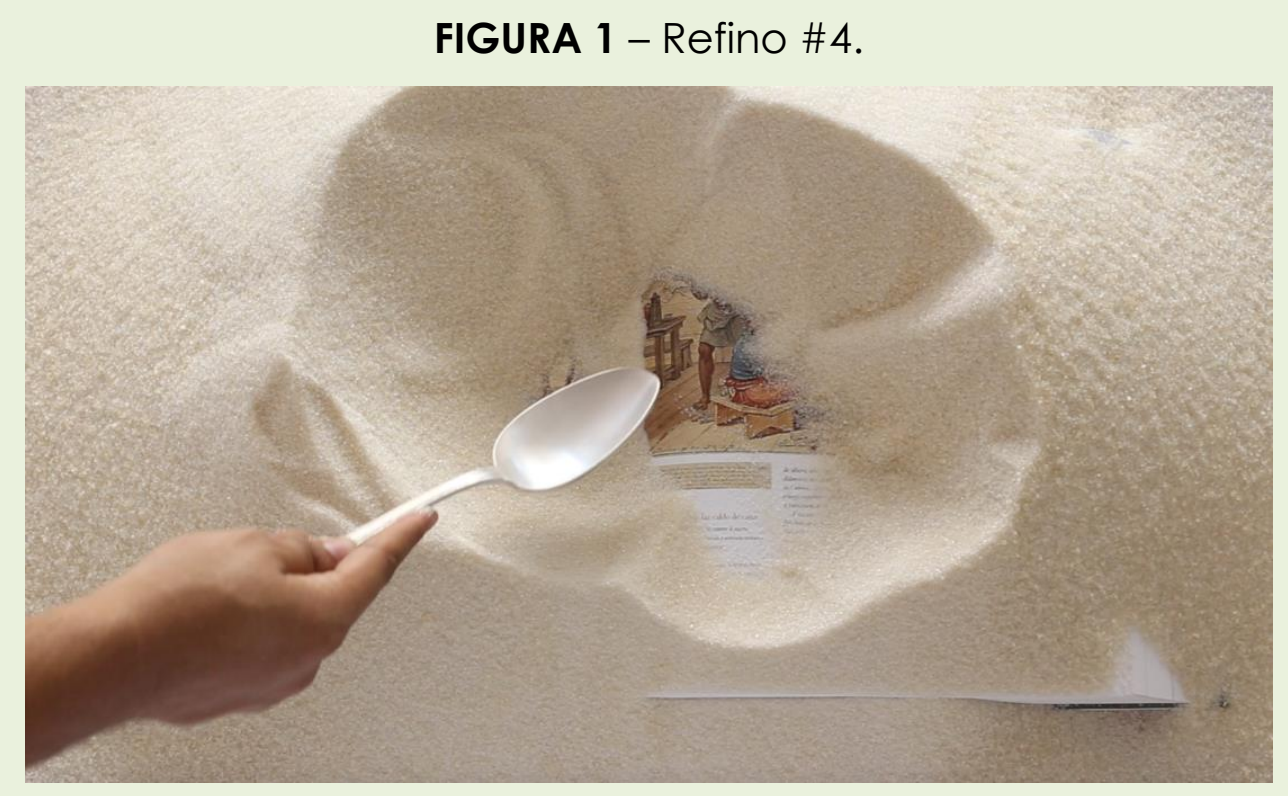

Fonte: [Artista: Tiago Santana. 2017].

No portfólio do artista, parte do texto que legenda a imagem da obra diz:

O açúcar aparece no vídeo a partir de uma necessidade de apagar a reprodução da violência, chamando atenção novamente para como o açúcar esteve e está presente na construção de estratificação social. E, ao mesmo tempo, escavar/revelar quão vil foi o processo colonial em torno da produção desse produto e o impacto que ele causa na atualidade um século depois do declínio desse modo de produção. O que é descortinado quando executamos uma arqueologia do açúcar?5

Já o texto que legenda a obra intitulada Apagamento \# 1 diz:

Fevereiro de 2015. 12 jovens negros têm suas vidas tiradas pela polícia militar no bairro do Cabula, em Salvador. Os jovens assassinados carregavam em seus corpos marcas raciais e sociais que os hierarquizaram historicamente como perigosos e abjetos. Nas periferias de Salvador, jovens estilizam seus cabelos por meio de desenhos realizados com navalhas. Nas cabeças, marcas internacionais ou palavras que revelam seus pertencimentos - um modo de representação e escrita de si. "Apagamento \# 1 (Cabula)" imerge nesse duplo contexto. O artista reproduz em seu cabelo a palavra "Cabula" e se fotografa, dia após dia, até que o nome desapareça completamente. O trabalho é uma estratégia de citar um processo cruel de extermínio e silenciamento sistêmico de jovens

5 Disponível em: <https://tiagosantanaarte.com/2017/10/19/refino-3-e-4/>. Acesso em: 15 fev. 2019. 
negros e de suas presenças nos contextos da metrópole soteropolitana. 6

FIGURA 2 - Apagamento \# 1

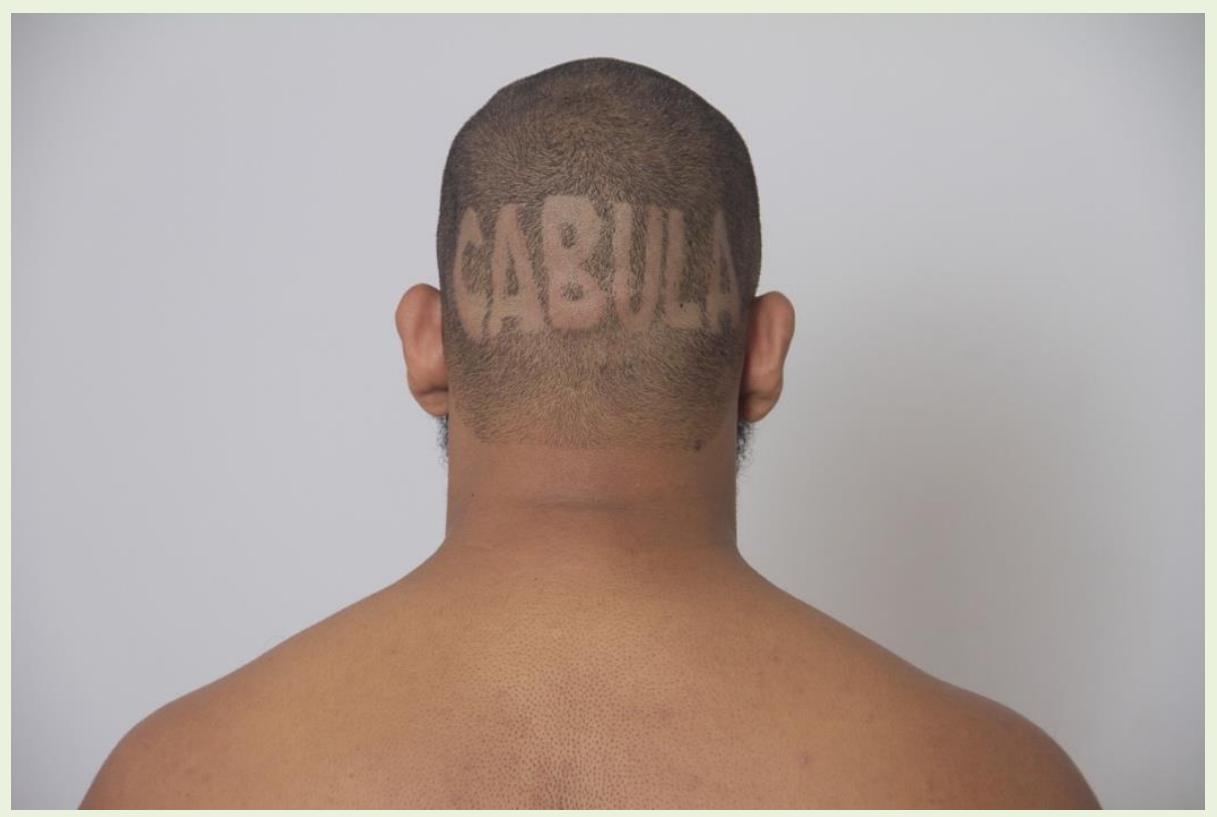

Fonte: [Artista: Tiago Santana. 2017].

A arte, aqui, funciona como um tipo de recurso para produzir novas e fortalecer velhas subjetividades, que contribuem eficazmente para um tipo de empoderamento cultural, racial, sexual, de gênero, de classe, de território... A arte que serve às causas democráticas e inclusivas.

O tema pode recair sobre o debate acerca da arte engajada, de uma arte motivada por uma causa justa, e da arte desinteressada, da arte que não está a serviço de nenhuma causa.

A crença numa arte que não quer dizer nada, que apenas expressa os sentimentos e emoções do artista, e que, não necessariamente, comunica, foi, durante muito tempo, vista como importante característica da obra de arte. Essa, a ideia de arte pela arte, de arte desinteressada. Entretanto, essa imagem da arte se tornou obsoleta no momento em que a arte passou a se relacionar com a economia. Para Gilles Lipovetsky e Jean Serroy, a hipermordenidade fez do artista desprovido de interesse pelas questões econômicas e mercenárias um artista interessado em dinheiro e fama. No

6 Disponível em: < https://tiagosantanaarte.com/2017/03/21/apagamento-1-cabula/>. Acesso em: 15 fev. 2019. 
momento em que os artistas contemporâneos mergulharam nos sistemas midiáticos-mercantis e assumiram que queriam ser ricos e famosos, o universo da arte assumiu um novo estatuto, qual seja, agora, "ele participa diretamente das leis do sistema midiático e econômico".

A concepção romântica do artista maldito, marginalizado por sua própria natureza e em ruptura com o sistema socioeconômico quanto mais se opõe ostensivamente ao dinheiro, valor estranho à arte, eminentemente corruptor e com o qual nenhum compromisso é possível, eclipsou-se. Ao menos desde que Warhol declarou: "Sou um artista comercial", ao confundir as fronteiras da arte, da moda e da publicidade, a situação mudou. Rejeitando a cantilena da pobreza como condição da pureza criadora, integrando-se de maneira ostensiva nos sistemas midiático-mercantis, os artistas contemporâneos aspiram a partir de então um objetivo claramente definido: ganhar dinheiro e ser célebres. O momento não é mais da glória imortal; é o da busca de uma celebridade midiática que assegure ser comprado e apanhado nas redes de promoção internacional. Fim da época de Van Gogh e das telas de valor póstumo do gênio desconhecido durante sua vida: o valor de uma obra não está mais apenas na gratuidade de seu sucesso estético; está primeiro e antes de tudo no seu preço de mercado. O êxito está na cotação do artista, que é inseparável de todo o trabalho de espetacularização e de provocação, de promoção midiática, de construção e de comunicação de uma imagem que passa pelos catálogos de exposição, pela rede internacional das galerias e das instituições culturais. Na era hipermoderna, ser artista não é mais apenas criar obras das quais se espera que sejam reconhecidas no futuro; é trabalhar em comunicar uma imagem, é figurar no Kunst Kompass, é estar cada vez mais presente e hipervisível no mercado mundial da arte. (LIPOVETSKY; SERROY, 2011 , p. 87-88).

Aqui, os autores chamam a atenção para o caráter comunicativo da obra de arte. Esse caráter é o que leva a manifestação artística ou a obra de arte, propriamente, a realizar a sua tarefa educadora e política, que é a de quebrar e romper representações classicamente negativadas sobre determinados grupos e comunidades, construindo novas imagens sobre ser periférico que fazem emergir novos modos de resistência e superação.

Para Bell Hooks (2010), a luta pela libertação dos negros demanda uma reconfiguração das representações produzidas sobre o negro. Nesse sentido, Hooks afirma que a hegemonia branca é da ordem da representação negativada sobre os negros. O que Hooks quer dizer é que a cultura visual, através de um bombardeio de imagens, reforça e reinscreve a 
supremacia branca. Por isso, a arte aparece como força potente, já que é construída no fenômeno da recepção. Como afirma Jean Caune (2012, p. 112), "a significação não é imediatamente presente: ela deve ser produzida por uma sensibilidade e um psiquísmo individuais; isto é, por um trabalho de associação sensível efetuado pelo receptor, ouvinte, espectador ou leitor".

Na performance Próxima, a artista e professora Sue Nhamandu ensina ao espectador-participante a encontrar a próstata feminina, o ponto $G$, nos recônditos de sua própria vagina. Ela trata o trabalho como uma aulashow, um tipo de ação artística educativa. O trabalho de Sue é uma excelente ilustração de como temas os mais variados, nesse caso, o sexo, podem servir à arte e à educação. Falar em sexo é educativo e artístico, a artísta educadora afirma. Funcionando com um tipo de educação sexual transmídia, a performance fez da artista a vencedora do $2^{\circ}$ Prêmio select de Arte e Educação.

FIGURA 1 - Próximo

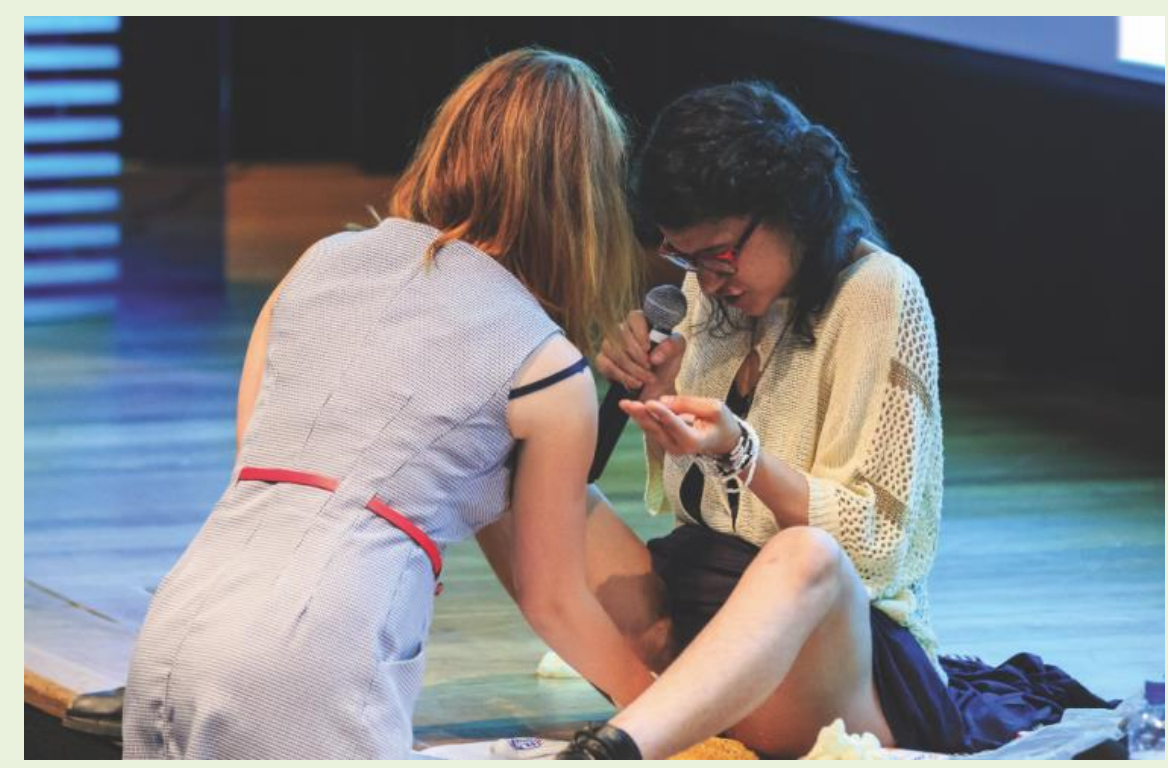

Fonte: [Artista: Sue Nhamandu. 2018].

Fora isso, a artista criou o conceito de Pornoklastia que une os termos pornografia e iconoclastia e subverte a lógica da imagética pornô mainstream, absolutamente falocêntrica, para "desmascarar a heterossexualidade como regime político, o gênero como performance, a 
ciência como uma mudança paradigmática politicamente conveniente e o patriarcado como obsoleto" 7 .

A obra da artista e educadora paulista Rosana Paulino é outro exemplo. Paulino chama a atenção para a violência sofrida por mulheres afrodescendentes no Brasil. Sua obra faz uma crítica voraz à escravidão e a seu legado no Brasil contemporâneo.

Na primeira imagem, a obra remete a uma colcha de retalhos feita com patuás costurados pela artista. A costura aprendida na infância serve para que a artista dialogue com os imaginários construídos acerca da composição racial brasileira. O trabalho de Paulino faz um percurso pela memória, que dá nome à obra: "Parede da Memória".

FIGURA 4 - Parede da Memória

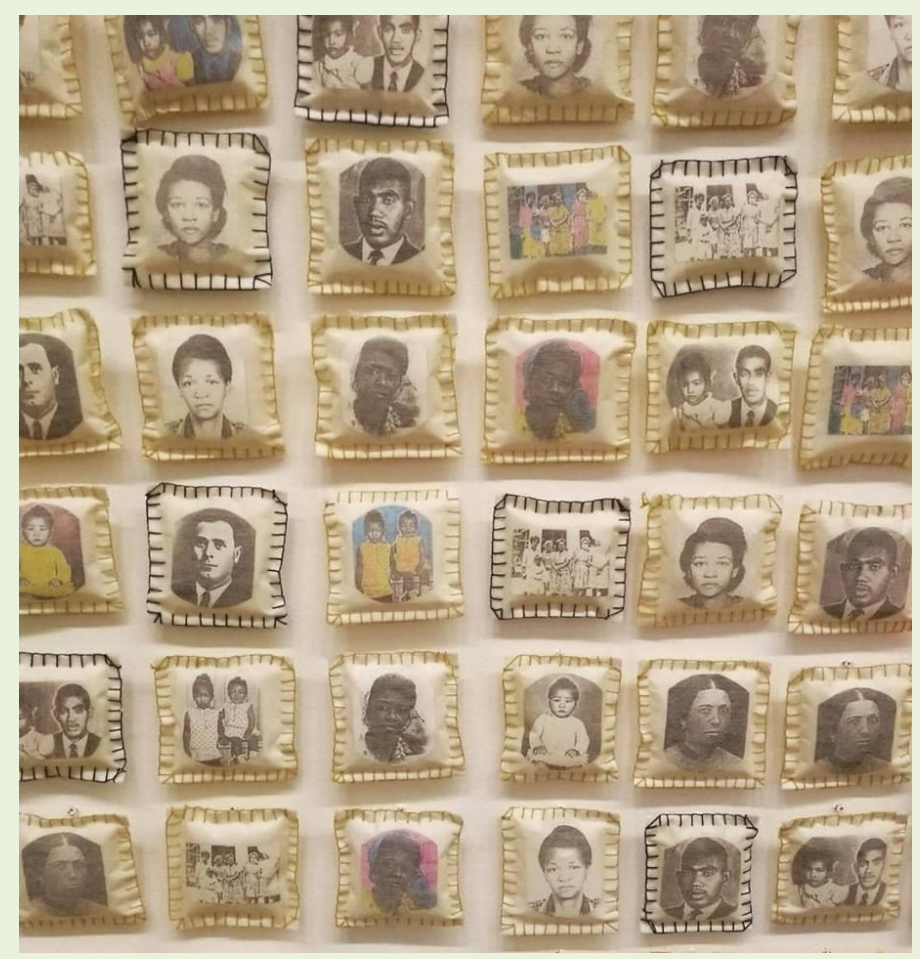

Fonte: [Artista: Rosana Paulino. 1994-2015].

Em outra obra, intitulada "Sem título (da série As três Graças)", Paulino utiliza vidros de relógio e cabelos. O que se vê é um conjunto de vidros, como bottons, com cabelos crespos colocados lado a lado com um

7 Imagem e texto disponíveis em: <https://www.select.art.br/educacao-sexual-transmidia/>. Acesso em: 22 fev. 2019. 
pedaço de cabelo liso e loiro. A obra chama a atenção para a valorização do cabelo crespo em oposição à perseguição de um modelo de cabelo valorizado pelo imaginário colonizado e embranquecido no Brasili.

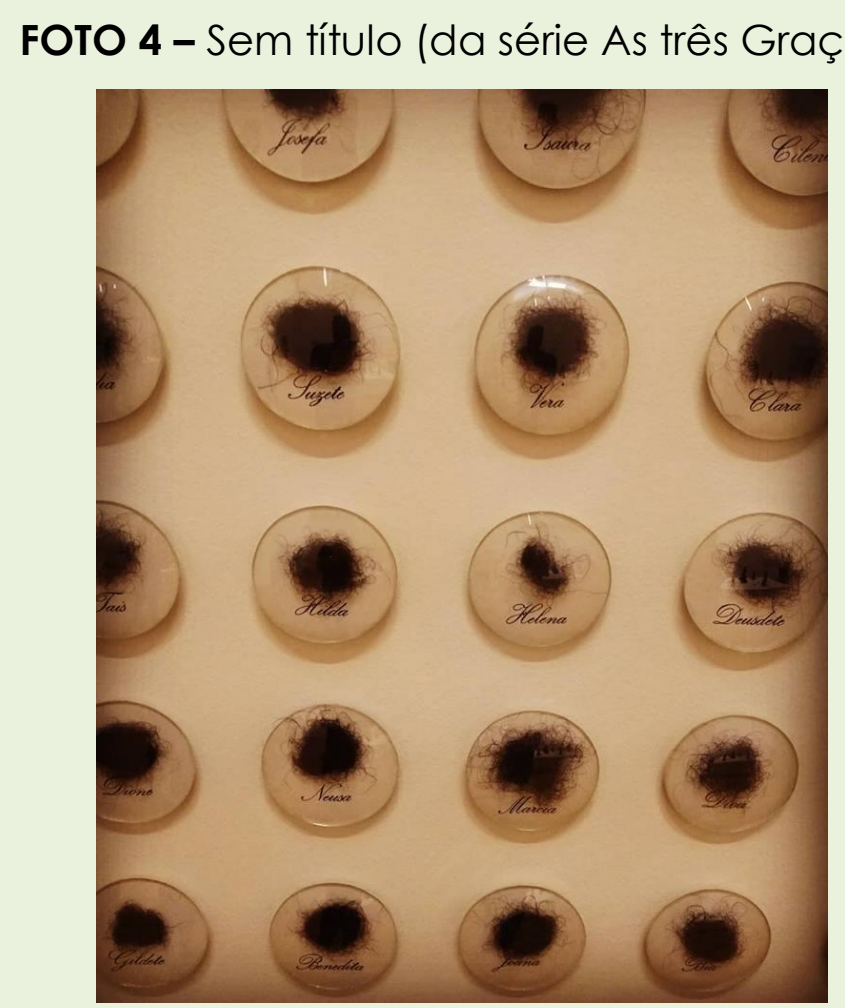

Fonte: [Artista: Rosana Paulino. 2006].

Se a arte é reveladora, produtora e restauradora de subjetividades, os imaginários e as expressões simbólicas são, por isso mesmo, os seus dispositivos maiores. Por isso, os três artistas, aqui ilustrados, não por coincidência, são educadores e, de certo modo, conciliam sua produção artística com o ensino e a aprendizagem, em tipos de ações e produções em artes que educam, que não servem somente à contemplação do belo, mas, sobretudo, que ensinam ao espectador da obra um pouco de história, de economia, de teoria queer, de teorias de gênero, de estudos de sexualidade, de nacionalismos e localismos, de raça e etnia, de ser pobre, "preto", "bixa" e vulnerável devido a sua condição de ser e existir.

8 Imagens extraídas da homepage da artista. Disponível em: <http://www.rosanapaulino.com.br>. Acesso em: 22 fev. 2019. 


\section{EDUCOMUNICAÇÃO COMO PROJETO EMANCIPADOR}

A história moderna, até pouco tempo, entendia a educação e a comunicação como campos autônomos. Uma, tinha a função específica de transmitir saberes. A outra, servia ao entretenimento e à informação. Por sua vez, a arte, como fonte de expressão, prestava-se a emocionar seu público e a transmitir os sentimentos do artista sobre as coisas e o belo.

A ideia de uma comunicação à serviço da educação surge no momento em que a inter-relação entre educação e comunicação faz emergir um novo campo de intervenção social, qual seja, a educomunicação. A importância desse acontecimento é que ele vai ao encontro de um outro fenômeno que é o da reformulação dos parâmetros que norteavam a arte-educação como projeto a favor do ensino das artes. Quando os paradigmas acerca de uma educação para a arte, isto é, da arte-educação, são reformulados, abandona-se seu papel exclusivo, traduzido pela utilização dos recursos educativos para ensinar ao aprendiz expressões artísticas e processos criativos. A partir de agora, no lugar da educação a serviço da arte apresenta-se uma arte a serviço da educação. Nesse campo de reconfiguração, expressões artísticas e processos criativos podem servir como instrumento de projetos de ensino e aprendizagem, como recursos pedagógicos, distanciados de uma educação com orientação técnica e tecnológica, pensada como componente de currículos, que apresentava a arte a serviço das legislações escolares. Da arte como forma de conhecimento ao conhecimento como forma de arte.

Ismael de Oliveira Soares defende a ideia de que a inter-relação entre comunicação e educação representa um sólido pressuposto político pedagógico. Entretanto, é necessário definir se essa inter-relação pode ser traduzida como um novo campo de conhecimento e ação ou se ela é, tão somente, fruto da interface entre dois campos definidos. O autor lembra que para os defensores da tese de que elas compõem tão somente uma simples interface, educação e comunicação se distanciam pelos seus discursos. 
O discurso educacional é mais fechado e enquadrador, oficial, mais autorizado. Validado por autoridades, não é questionado. Neste sentido, é autoritário, posto que é selecionado e imposto em forma de currículo a alunos e professores. O discurso comunicacional, ao contrário, é desautorizado, desrespeitoso e aberto, no sentido de que está sempre à procura do novo, do diferente, do inusitado. Enquanto a educação está presa ao Estado fragilizado, sem poder e pobre, naquilo que o Estado tem de pior, que é a burocracia; a comunicação vincula-se ao mercado, aprimora-se constantemente, tem liberdade na construção do seu "currículo" e de sua forma de agir (SOARES, 2000, p. 18).

Ainda segundo Soares, para os que defendem o perfil integrador da inter-relação entre comunicação e educação, o mais importante nesse novo campo é a interdiscursividade ou, melhor, a polifonia interdiscursiva.

Não se trata, pois, de educar usando o instrumento da comunicação, mas que a própria comunicação se converta no eixo vertebrador dos processos educativos: educar pela comunicação e não para a comunicação. Dentro desta perspectiva da comunicação educativa como relação e não como objeto, os meios são ressituados a partir de um projeto pedagógico mais amplo (Soares, 2000, p.2).

Nesse sentido, a arte e a comunicação, no que se apresentam como importantes elementos de produção de sentidos, assumem seu papel de fomentadoras do fenômeno social, já que conferem às práticas sociais o poder de formar sujeitos sociais.

As atividades humanas se realizam nas práticas sociais, mediadas por diferentes linguagens: verbal, corporal, visual, sonora e, contemporaneamente, digital. Por meio dessas práticas, as pessoas interagem consigo mesmas e com os outros, constituindo-se como sujeitos sociais. Nessas interações, estão imbricados conhecimentos, atitudes e valores culturais, morais e éticos (BRASIL, 2019).

\section{EU SÓ QUERO É SER FELIZ}

A arte, a comunicação e a educação são políticas quando estão preocupadas com o fortalecimento de projetos promotores de iniciativas inclusivas, democráticas, contra-hegemônicas. Na contemporaneidade, assistimos ao surgimento e à multiplicação de ações e iniciativas apoiadas na especificidade de interesses, problemas, prioridades e causas dos grupos e das comunidades juridicamente vulneráveis. Entre essas iniciativas, 
encontra-se o emergente mercado de arte e cultura produzido na e a partir da periferia que, desde a década de 1980, tem impactado o mercado dominante, o mainstream da arte e da cultura nos centros urbanos globais.

Esse mercado underground tem se constituído através da emergência de expressiva produção artística, aonde se inclui importante produção literária, que promove a valorização a pertencimentos étnicos, sexuais, locais e culturais, concretizada pela emergente proliferação de coletivos, de saraus, de slams, pelo surgimento de mais e mais artistas que falam da e desde a periferia (escritores, poetas, videomakers, dançarinos, performes); pelo fortalecimento do mercado editorial alternativo, artesanal, marginal; pelo surgimento de bibliotecas comunitárias, de bibliotecas móveis; pelo uso da Internet como recurso para produção e distribuição de textos; pelo teatro de rua; pela dança de rua, a street dance; pelo cinema do gueto; pela produção de vídeos feita das margens; pela emergência dos movimentos sociais e por um tanto de outras iniciativas, que contribuem radical e positivamente para a consolidação de um novo nicho artístico e literário que, quando não forma produtores ativos ou realizadores não passivos, forma, minimamente, públicos conscientes.

Essa emergência de produções e de produtores das margens não foi uma particularidade do caso brasileiro, mas, de modo geral, um caso das periferias globais que impuseram uma nova lógica de ver e pensar a produção artística e, por extensão, a hegemonia de mercado, através de ações de ativismo cultural e artístico. A particularidade do Brasil é que, pelo fato de ter $6 \%$ da sua população vivendo em favelas e, em algumas capitais, esse número chegar a mais de $50 \%$ da população, como no caso de Belém, a força das produções das periferias foi arrebatadora, tantos em seus termos quantitativos como qualitativos. Por isso, o país virou referência na produção de emergência da periferia, dos atores da periferia, das expressões artísticas e culturais da periferia.

A arte das margens é sempre uma arte política. Não importa de que margem estamos falando. 
[...] a arte não é política antes de tudo pelas mensagens que ela transmite nem pela maneira como representa as estruturas sociais, os conflitos políticos ou as identidades sociais, étnicas ou sexuais. Ela é política antes de mais nada pela maneira como configura um sensorium espac,o-temporal que determina maneiras do estar junto ou separado, fora ou dentro, face a ou no meio de... Ela é política enquanto recorta um determinado espaço ou um determinado tempo, enquanto os objetos com os quais ela povoa este espaço o ou o ritmo que ela confere a esse tempo determinam uma forma de experiência específica, em conformidade ou em ruptura com outras: uma forma específica de visibilidade, uma modificação das relações entre formas sensiveis e regimes de significação, velocidades específicas, mas também e antes de mais nada formas de reunião ou de solidão. Porque a política, bem antes de ser o exercício de um poder ou uma luta pelo poder, é o recorte de um espac,o específico de "ocupações comuns"; é o conflito para determinar os objetos que fazem ou não parte dessas ocupações, os sujeitos que participam ou não delas, etc. Se a arte é política, ela o é enquanto os espaços e os tempos que ela recorta e as formas de ocupação desses tempos e espaços que ela determina interferem com 0 recorte dos espaços e dos tempos, dos sujeitos e dos objetos, do privado e do público, das competências e das incompetências, que define uma comunidade política (RANCIERE, 2019, p. 1).

Esse projeto de tomar voz pelos subalternizados, além de político, é sempre educativo, já que contribuem para o alargamento do próprio conceito de educação. Aqui, a educação é construtora, mais que instrutora. Foge aos padrões da educação conteudista e bancária e se alinha a uma frente do que o educador Reinaldo Fleuri tratou como sendo uma educação para a alteridade, uma educação que legitima o Outro como produtor de conhecimento.

Tal perspectiva configura uma proposta de "educação para a alteridade", aos direitos do outro, à igualdade de dignidade e de oportunidades, uma proposta democrática ampla que, no mundo anglo-saxão, se define como Multicultural Education (EUA, Canadá, Grã-Bretanha), e que, nos outros países da Europa, assume diferentes denominações: pedagogia do acolhimento, educação para diversidade, educação comunitária, educação para a igualdade de oportunidades ou, mais simplesmente, educação intercultural. Por este motivo, Stephen Stoer e María Luiza Cortesão, de Portugal, têm utilizado o termo educação inter/multicultural para indicar o conjunto de propostas educacionais que visam a promover a relação e o respeito entre grupos socioculturais, mediante processos democráticos e dialógicos (FLEURI, 2005, p. 93).

Por isso, mesmo que não reconheçamos nesses projetos elementos clássicos da educação escolarizada, devemos atentar para o papel de 
construtora e transformadora de subjetividades que esse tipo de iniciativa apresenta. Afinal, como já vimos, a arte é produtora de subjetividades, restauradora de imaginários e geradora de expressões simbólicas.

O Coletivo Afrobapho, criado como expressão de artivismo produzida na e desde a periferia de Salvador por um movimento de representatividade das dissidências sexuais é exemplo. Surge, num primeiro momento, como performance digital, uma expressão artística, que exalta a utopia; mas que, agora, a apresenta nos seus termos sociológicos, através de ações de resistência e do uso das mídias digitais, num tipo de artivismo, aqui definido como o uso artístico das tecnologias de informação e comunicação, que é um tipo de ativismo social e político, que tem nas expressões em arte e cultura seus instrumentos maiores. Por isso, pode-se afirmar que o Coletivo Afrobapho é uma criação estética que integra o conjunto de recentes ações políticas que alimentam "uma postura crítica sobre a função da arte e da mídia na sociedade contemporânea" (FOLLETO, 2018, p. 106).

O papel pedagógico desse tipo de iniciativa reside no fato de que a cultura e a arte produzida por sujeitos, grupos e comunidades à margem das histórias oficiais da cultura tem assumido importante papel junto aos fluxos de combate às culturas hegemônicas, já que têm funcionado como importantes instrumentos de resistência, num tipo de manifestação de cultural e artística aliada às causas dos movimentos sociais, o dito artivismo.

Alan Costa relata que a experiencia de gravar vídeos nas ruas, onde há movimentação de pessoas, é uma maneira de trazer para o mundo offline o debate feito pelo Afrobapho dentro das redes sociais, no mundo online. Desse modo, mesmo a escolha do cenário é uma ação política e pedagógica, já que ensina não somente ao espectador do vídeo, mas, também, ao morador do cenário no qual está sendo produzido o vídeo. Alan acredita que é importante tornar corriqueiras representações que, habitualmente, não são vistas no cotidiano de parcela significativa da população, por mais que os cenários sejam familiares. O performer defende a ideia de que a reincidência de tais representações contribui para naturalizar realidades antes vistas como distantes para expressiva parcela da 
população brasileira, mesmo que sejam recorrentes para outra importante parcela.

\begin{abstract}
Até mesmo quando a gente foi gravar o vídeo "Bixa Preta" na favela de Sussuarana, encontramos essas resistências. Mas, esses são os corpos que existem na favela. Inclusive, as bichas pretas são outro exemplo de "dar a cara a tapa", porque elas se criam na favela e performam sua identidade, bem longe do conceito do que é queer ou do que é dito pela academia. Foi interessante gravar lá porque representa as vivências de muitas bichas pretas das favelas daqui de Salvador, e pessoas do Rio também se identificam muito com isso. E eu acho que as pessoas precisam se incomodar mesmo, porque se não incomodar não faz sentido pra gente. A gente quer causar estranhamento fazendo as pessoas refletirem. A gente usa muito esse discurso de "porque as pessoas não gostam ou não respeitam quem nós somos ou como nós queremos nos portar na sociedade, se a gente diretamente não atinge nenhum deles?". Usamos esse discurso pra mostrar que a gente, sendo quem nós somos, estamos querendo o nosso lugar no mundo (sic.) $)^{9}$.
\end{abstract}

O video Bixa Preta a que Alan se refere é, na verdade, o Projeto Da Quebrada, inspirado na música Bixa Preta, da Mc Linn da Quebrada, acima citada. No canal do Coletivo no Facebook, o texto de apresentação do Projeto diz:

Da Quebrada é uma amostra audiovisual do Coletivo AfroBapho em parceria com Edgar Azevedo (Laiá Films). O projeto é inspirado na artista Linn da Quebrada, um dos grandes nomes da geração atual em relação ao ativismo lgbł preto. Em sua música, intitulada Bixa Preta (tema do vídeo), ela narra a vivência de bixas pretas faveladas, que lidam com vários tipos de opressões, resistindo e sobrevivendo em uma sociedade desigual, racista e lgbtfóbica. Geralmente marginalizadas pelo sistema, as bixas pretas conseguem usar o corpo e a contravenção de padrões heteronormativos como armas para legitimar suas existências. O projeto foi gravado no Bairro de Sussuarana (Salvador), com jovens pretos moradores ${ }^{10}$.

O uso do corpo como suporte para a ação política não é um fato recente. Ao inscrever no corpo elementos culturais que o traduzirão como lugar de exercício de poder, as sociedades humanas, através das mais diversas criações simbólicas, elaboraram modos de dominação que

\footnotetext{
9 Entrevista com Alan Costa realizada por Lucas Santos, em Salvador, no dia 07 de junho de 2018. Dados da entrevista podem ser encontrados em SANTOS e FREITAS, 2019. Aliás, parte desse artigo não teria sido possível sem a valiosa parceria e contribuiçao de Lucas Santos.

10 Disponível em: <https://www.youtube.com/watch??=0LOdJTwWjk8>. Acesso em: 20 out. 2018.
} 
legitimaram a formação de escalas de privilégio e prestígio. Na última década, chama a atenção o fato de o corpo ser utilizado como suporte para elaborar expressões artísticas que funcionam como ações críticas e, por isso, políticas, frente à uma realidade cada vez mais virtualizada. Por isso, mesmo que parte do ativismo que utiliza a arte para manifestar-se seja feito no espaço público, outra parte é feita na e a partir da Internet, através das mídias digitais. Nelas, o corpo que fala, o corpo que dança, o corpo que veste ou despe é corpo insurgente, marcado por subjetividades e identidades desconsideradas, silenciadas, marginalizadas ou invisibilizadas nas esferas tradicionais do poder.

Nesse sentido, prioridades e demandas cultivadas no âmbito da militância social são expressas por sujeitos e grupos que, vulneráveis juridicamente, são chamados artivistas, quando interrelacionam arte e ativismo político.

Fernando Gonçalves defende a ideia de que coletivos artísticos estão mais compromissados com o político, que, propriamente, com a política, pois o político traduz a atuação do indivíduo enquanto ser e agente transformador na sociedade, ao passo que a política está comumente relacionada aos partidos, aos sindicatos e às associações. Por isso, pode-se afirmar que movimentos artivistas atuam "fora dos meios culturais institucionalizados e, frequentemente, junto a movimentos sociais" (GONÇALVES, 2012. p. 181). E é pelo fato de atuarem junto a movimentos sociais que se organizam em forma de coletivos, que, por sua vez, fazem a mediação entre as artisticidades, o ativismo, a mídia e as causas sociais e políticas.

No Brasil, o movimento LGBT+ tem se destacado na criação de coletivos e práticas midiartivistas a fim de evocar demandas e pautas da comunidade, num tipo de pedagogia da militância, de pedagogia ativista, de uma atuação educativa encontrada na militância ativista.

Seja para celebrar subjetividades, abordar realidades marginalizadas ou denunciar preconceitos, os campos das artes interseccionadas ao 
ativismo e às ações educativas vem sendo explorados de maneira expressiva.

Leandro Colling chama a atenção para a recorrência de propostas de artivismo de dissidencias sexuais e de gênero nos últimos anos, quando "uma série de artistas produz, por meio de variadas linguagens, diversos discursos que questionam os binarismos, as naturalizações e normatizações relativas a gênero e sexualidade" (COLLING, 2017, p.18). Mas, há, ainda, uma série de outras pautas organizadas em torno do artivismo, das ações e práticas educativas e do uso das mídias digitais, como as dos coletivos negros e dos coletivos feministas.

Essas ações, advindas das margens, das periferias, tem assumido importante papel ao contrapor modelos de pensamento canônicos, forças hegemônicas e, combativamente, atribuir novos sentidos políticos às causas, aos problemas e às prioridades das comunidades subalternizadas no contexto do neoliberalismo.

São iniciativas que têm servido ao dito ativismo social, num tipo de midiartivismo educativo, que, mesmo quando está à margem do sistema, à margem do mercado e dos projetos tecnologicamente direcionados, que mesmo quando nega as histórias oficiais da cultura, tem poder crítico e, por isso, interpela, não somente a comunidade, mas também, as culturas hegemônicas, as culturas centrais, num tipo de produção crítica, de enfretamento, naquilo que Heloísa Buarque de Hollanda cunhou, na primeira década dos anos 2000, como sendo fruto das "novas periferias", naquele caso, literárias, que "vêm se redefinindo em função das lógicas dos processos de globalização neoliberal" e provocando importantes "enfretamentos culturais ao contexto político e econômico do século XXI", ou seja, a "literatura e a cultura produzida na periferia das grandes cidades brasileiras e seu poder de interpelação e impacto na produção canônica e de massa"(HOLLANDA, 2017). 


\section{CONCLUSÃO}

Artistas e coletivos educadores sintetizam o sentido que confere poder e visibilidade à coletividade organizada em torno do movimento e das militâncias sociais. O corpo, aqui, funciona como midia radical alternativa, aos moldes do defendido por John Downing, já que informa, comunica e constrói discursos. Grupos contra-hegemônicos, através das mais diversas estratégias discursivas, como as mídias e o corpo, promovem um tipo de "mídia geral de pequena escala e sob muitas formas diferentes - que expressa uma visão alternativa às políticas, prioridades e perspectivas hegemônicas" (DOWNING, 2004, p. 21).

Expressiva parcela dos coletivos do segmento LGBT+, por exemplo, ao realizar produções que utilizam corpos, vozes e vivências para comunicar pautas, num tipo de pedagogia queer, subverte normas e ideários cristalizados sobre o que é movimento social, arte e pedagogia. A estética da derrisão comportamental, da performatividade queer, do lacre, do arraso e do desbunde diz respeito ao uso da estética como aliada: "as diversas formas que a juventude viada, trans, sapata tem encontrado para se fortalecer e se defender são verdadeiras obras de arte dentro do universo virtual" (FILHO; NASCIMENTO, 2017, p. 544).

Judith Butler chamará de performatividade queer a força política da citação descontextualizada de um insulto homofóbico e da inversão das posições de enunciação que esse provoca. Por exemplo, a palavra sapatona passa de insulto pronunciado pelos sujeitos heterossexuais para marcar as lésbicas como "abjetas" para se transformar, posteriormente, em uma autodenominação contestadora e produtiva de um grupo de "corpos abjetos" que, pela primeira vez, tomam a palavra e reclamam sua própria identidade" (BUTLER apud PRECIADO, 2017, p. 28). Por isso, o lacre político, ou mesmo, o artivismo, não se limita apenas às questões do âmbito da política, mas, sobretudo, às formas e composição estéticas. O Afrobapho, por exemplo, ao fazer política, cria volumosos ensaios fotográficos, produz audiovisual, primorosos gifs e memes e toda a sorte de expressões de criatividade, que tanto têm função estética, voltada para o prazer da 
fruição, como política, ao comprometerem-se com a pauta da dissidência sexual.

É necessária atenção especial a esses novos movimentos e tipos de produção, frutos da contraconduta e da subversão dos que se munem de armas estéticas para fazer ecoar suas vozes. O advento da Internet intensifica essas novas configurações politicas, mais libertárias e não menos eficientes, permitindo o surgimento de novas vozes, que incidem sobre a liberdade de novos corpos e subjetividades. Essa nova forma de fazer política, calcada na exploração do corpo e, muitas vezes, no riso e no desbunde como instrumentos de transformação e de uma política educativa, quase sempre é considerada estranha e deslegitimada por quem somente acredita na maneira autoritária e burocrática do fazer político. Corpos queers, estranhos, mas não alheios à luta por representatividade, quebram paradigmas e contribuem para $o$ aniquilamento dos discursos de ódio.

Essa é, portanto, uma perspectiva dissidente, que propõe narrativas autogeridas, a fim de promover o debate sobre demandas sociais por meio de linguagens estéticas disruptivas, radicais e provocativas, fazendo dos "engajamentos uma possibilidade de afirmação e desobstrução de fluxos de vida e não apenas uma experiência marcada pela negação" (GONCşALVES, 2012, p. 179).

Nesse contexto, as formas de existência e resistência se manifestam através de performances múltiplas, criativas e carregadas do teor crítico, ressignificando, através da arte, uma realidade que cerceia liberdades de expressão e de pensamento.

Não mais arte desinteressada, arte pela arte, contemplativa, que marca o distanciamento entre quem frui do objeto da arte e quem o produz. O que se vê, agora, são expressões em arte interessada, engajada, militante, educativa. Arte que está na rua, que está no corpo, que está em nós.

São ações educativas que tanto dizem respeito às formas de corporeidades, aos jeitos de corpo, assim como às visualidades, rompem com as normas e regras de comportamento canônicas, paradigmáticas, 
heteronormativas, hegemônicas, ao apresentar para o mundo corpos e espíritos libertos, livres das amarras moralistas. Essas ações contribuem para a emancipação de outros jovens, ao perceberem a possibilidade de escapar dos "cerceamentos que acometem sobretudos os indivíduos que se veem diferentes e ao mesmo tempo solitários em sua suposta singularidade" (FILHO; NASCIMENTO, 2017, p. 544), ao encontrarem nos coletivos o enaltecimento das condições ou das características que os afligem ou condenam.

É arte que vem das quebradas para quebrar paradigmas, que revela a beleza do que foi considerado inóspito por muito tempo, a partir da reiteração de discursos que encontravam respaldo nos meios de comunicação hegemônicos e nos sistemas institucionalizados clássicos da educação a fim de se perpetuarem. É o levante das dissidências que não permitem que sejam silenciadas e se nutrem de estratégias para vencer 0 apagamento, a marginalização e o alijamento. É a arte que "extrapola os limites do quadro, da moldura e até mesmo das paredes do museu [...] para instalar-se na realidade absoluta, na vida cotidiana" (FREITAS, 2007, p. 86). É o artivismo que se conecta com seus públicos. São as ações educativas que, a favor da transformação, reestruturam relações de poder e reorganizam as esferas de privilégio e prestígio.

\section{REFERÊNCIAS BIBLIOGRÁFICAS}

BRASIL. Ministério da Educação. Governo Federal. Base Nacional Curricular Comum: BNCC. Disponível em: <http://basenacionalcomum.mec.gov.br/wpcontent/uploads/2018/12/BNCC_19dez2018_site.pdf>. Acesso em: 22 fev. 2019.

BUTLER, J. Problemas de gênero: feminismo e subversão da identidade. Rio de Janeiro: Civilização Brasileira, 2003.

CAUNE, J. Cultura e comunicação: convergências teóricas e lugares de mediação. São Pualo: Editora UNESP. 2012.

COLLING, L. Artivismo das dissidências sexuais e de gênero. Revista CULT. Ano 20. Agosto de 2017. 
DOWNING, J. Mídia radical: rebeldia nas comunicações e movimentos sociais. São Paulo: Editora Senac, 2004.

FILHO, A. V.; NASCIMENTO, R. T. Práticas da imagem e produc,ão de vidas: Insurgencias curriculares visuais, estéticas e culturais nas redes. Revista Brasileira de Pesquisa (Auto) Biográfica, Salvador, v. 02, n. 06. 2017.

FLEURI, R. M. Intercultura e educação. Educacao, sociedades e cultura. n. 23. Disponível em: < https://www.fpce.up.pt/ciie/revistaesc/ESC23/23Reinaldo.pdf>. Acesso em: 24 fev. 2019.

FOLETTO, L. F. Midiativismo, midia alternativa, radical, livre, tática: um inventário de conceitos semelhantes. In: BRAIGHI, Antônio Augusto; LESSA, Cláudio; CAMARA, Marco Túlio (orgs.). Interfaces do Midiativismo: do conceito à prática. CEFET-MG: Belo Horizonte, 2018. P. 95-110.

Freire, P. Extensão ou comunicacão? $7^{a}$ ed. Rio de Janeiro: Editora Paz e Terra, 1983.

Freire, P. Pedagogia da autonomia. Rio de Janeiro: Paz e Terra, 2010.

FREITAS, R. O. A periferia da periferia: mídias alternativas e cultura de minorias em ambientes não-metropolitanos. Especiaria. v. 10, n. 17. Ilhéus: Editus. 2007.

GADOTTI, M. Perspectivas atuais da educac,ão. São Paulo em perspectiva. Vol. 14. N. 2. Disponivel em:

<http://www.scielo.br/scielo.php?script=sci_arttext\&pid=s0102$88392000000200002>$. Acesso em: 24 fev. 2019.

GONCALALS, F. N. Arte, ativismo e usos das tecnologias de comunicação nas práticas políticas contemporâneas. Contemporânea, v. 10, n. 2, nov. 2012. Disponivel em: <http://www.epublicacoes.verj.br/index.php/contemporanea/article/view/2234>. Acesso em: 31 mai. 2018.

HOLLANDA, H. B. Literatura marginal. Disponível em:

<http://www.heloisabuarquedehollanda.com.br/literatura-marginal/>. Acesso em: 10 de janeiro de 2017.

HOOKS, B. Eros, erotismo e o processo pedagógico. In: LOPES, Guacira Louro (Org.). O corpo educado: pedagogias da sexualidade. 2.ed. Belo Horizonte: Autêntica, 2010.

LIPOVETSKY, G.; SERROY, J. A cultura-mundo: resposta a uma sociedade desorientada. São Paulo: Companhia das Letras, 2011.

LOURO, G. L. Um corpo estranho: ensaios sobre sexualidade e teoria queer. $2^{a}$ ed. Belo Horizonte: Autêntica Editora, 2013. 
LOURO, G. L. Teoria Queer: uma política pós-identitária para a educação.

Estudos Feministas. n. 2. Ano 2001. Acesso em disponível:

<http://www.scielo.br/pdf/ref/v9n2/8639.pdf>. Acesso em 10 fev. 2019.

MARTIN-BARBERO, J. O ofício do cartógrafo. São Paulo: Edições Loyola. 2004.

PRECIADO, P. B. Manifesto Contrassexual: práticas subversivas de identidade sexual. São Paulo: N-1 Edições, 2017.

RANCIÈRE, J. Política da arte. Disponível em:

<https://perfopraticas.files.wordpress.com/2011/09/ranciere-jacques-

apolc3adtica-da-arte.pdf>. Acesso em: 18 fev. 2019.

SANTOS, L. M. e FREITAS, R. O. Lacre político: artivismo dissidente do Coletivo Afrobapho. Contexto - Revista do Programa de Pós-Graduação em Letras. Acesso em: <http://periodicos.ufes.br/contexto/article/view/23026/15559>. Acesso em 10 fev. 2019.

SILVA, T. T. Documentos de Identidade - uma introduc,ão às teorias do currículo. Belo Horizonte: Autentica, 2007.

SOARES, I. O. Educomunicação: um campo de mediac,ões. In: Comunicacãa \& Educacãáo. Revista do Departamento de Comunicac,ão e Artes da Universidade de São Paulo. a. 7, set.2000, p. 12-24.

Recebido em: 24 de fevereiro de 2019 Aprovado em: 23 de agosto de 2019 